\title{
Design of Derivative-free State Estimators for a Three Phase Induction Motor - A Comparative Study
}

\author{
J. Ravikumar \\ Assistant Professor \\ Dept. of Electrical Engg \\ Annamalai University \\ Annamalai Nagar, India.
}

\author{
S. Subramanian \\ Professor \\ Dept. of Electrical Engg. \\ Annamalai University \\ Annamalai Nagar, India.
}

\author{
J. Prakash \\ Associate Professor \\ Dept. of Instrumentation Engg. \\ Madras Institute of Tech. \\ Chennai - 44, India.
}

\begin{abstract}
Particle filters are an alternative to approximate the Kalman filter for nonlinear problems. This paper intends to assess the potential of Particle Filter (PF) and its variants in the context of the state estimation problem of a three phase induction motor. The conventional Particle Filter (SIR-PF), and particle filters that employ importance sampling through proposal distributions such as Particle Filter with Extended Kalman Filter (PF-EKF) and Particle Filter with Unscented Kalman Filter (PF-UKF), which are proposed in the literature within the particle filtering framework that takes into account of the latest observational information to reduce the risk of weight degeneracy is described and the error behaviour is analyzed through Monte Carlo simulations with regard to three scenarios Viz., low speed operation, step changes in load torque and reversal of speed. Simulation results demonstrate the superior tracking performance of PF-EKF at the expense of higher computational effort over the other approaches and can be determined to be a good substitute for the UKF in terms of accuracy of the state vector estimation.
\end{abstract}

\section{Keywords}

Unscented Kalman Filter (UKF), Particle Filter with EKF as Proposal Distribution [PF-EKF], Particle Filter with UKF as Proposal Distribution [PF-UKF], Sampling Importance Resampling Particle Filter [SIR-PF], Bayesian State Estimation, Three Phase Induction motor [IM].

\section{Nomenclature}

$\begin{array}{ll}\mathrm{P}_{\mathrm{p}} & \text { No. of pole pairs } \\ \mathrm{L}_{\sigma}=\sigma \mathrm{L}_{\mathrm{s}} & \text { Stator transient inductance }(\mathrm{H}) \\ \sigma & \text { Leakage or Coupling factor } \\ \mathrm{L}_{\mathrm{s}} & \text { Stator inductance }(\mathrm{H}) \\ \mathrm{R}_{\mathrm{s}} & \text { Stator resistance }(\Omega) \\ \mathrm{L}_{\mathrm{r}}^{\prime} & \text { Rotor inductance referred to the stator side } \\ \mathrm{R}_{\mathrm{r}}^{\prime} & (\Omega) \\ \mathrm{V}_{\mathrm{s} \alpha}, \mathrm{V}_{\mathrm{s} \beta} & \text { Rotor resistance referred to the stator side }(\Omega) \\ \psi_{\mathrm{r} \alpha}, \psi_{\mathrm{r} \beta} & \text { Stator stationary axis components of stator } \\ & \text { currents (V) } \\ & \text { Rotor stationary axis components of stator } \\ & \text { flux (V-s) }\end{array}$

$\begin{array}{ll}\mathrm{J}_{\mathrm{L}} & \text { Total inertia of the IM }\left(\mathrm{Kg} \cdot \mathrm{m}^{2}\right) \\ \omega_{\mathrm{m}} & \text { Angular velocity (rad-s) }\end{array}$

\section{INTRODUCTION}

State estimation can be considered as an optimal solution within a Bayesian framework. The pioneering work of Kalman (1960) provides an exact solution to the problem of state estimation for linear systems with Gaussian additive noises. Later, Kalman Filter (KF) was modified to give the Extended Kalman Filter (EKF) to accommodate lightly nonlinear systems, and this is basically the dominant Bayesian state estimation algorithm for nonlinear systems and non-Gaussian uncertainties over the past four decades [2-7]. The covariance propagation step in the EKF requires linearization of nonlinear system dynamics around the mean. When the system dimension is large, computing derivatives of nonlinear state transition and measurement functions at each time step can prove to be a computationally demanding exercise [8], [9].

Alleviating difficulties arising due to the computation of the Jacobian has been the main motivation behind a new class of derivative free Kalman filter, such as the Unscented Kalman Filter (UKF) proposed by Julier and Uhlmann (2000) that have recently appeared in the literature. When compared to the EKF, the derivative free filters can be used for state estimation in a much wider class of nonlinear systems. For inputs with non-Gaussian distributions, Julier and Uhlmann (2004) have shown that the $\mathrm{UKF}$ results in approximations that are accurate to at least the second-order; while the third and the higher order moments can also be approximated with good accuracy by appropriately choosing the tuning parameters.

Literature concerning the implementation of UKF for the estimation of hidden states from noisy data for a three phase induction motor is rather limited and there have been a very few papers published in the literature [10-12]. The advantage of using the unscented transform as a nonlinear approximation by showing faster convergence of the UKF against the EKF using the example of the induction machine with poor initial estimates is very well demonstrated in [12]. The reason for enhanced performance of $\mathrm{UKF}$ is attributed to better nonlinear approximation at each step [13]. The UKF as a tool for state estimation seems to be a promising alternative for process control applications. However, the UKF algorithm is computationally more intensive than EKF [12]. 
Another alternative to approximate Kalman filtering problem for nonlinear problems is to use sequential Monte Carlo methods also known as particle filters. Essentially, Particle Filter (PF) is a method of recursive Bayesian filtering by Monte Carlo simulations. It is based on the Sequential Importance Sampling (SIS) algorithm; the key idea is to represent the posterior probability density function (PDF), by a set of random samples with associated weights. Particle filters use a number of particles to represent the PDF of the system states. The estimates are computed based on those samples and weights. With large number of samples, this Monte Carlo characterization becomes an equivalent representation to the usual description of the posterior PDF, and the SIS filter approaches the optimal Bayesian estimation. An authoritative and lucid survey of PF's can be seen in [14] and [15], as well as cautionary tales and the state-of-the-art theory on the issue of high dimensional problems with regard to particle filters in [16].

An increase in the use of particle filtering schemes was seen with the introduction of the re-sampling technique by Gordon et al., (1993). A common problem that is associated with the implementation of particle filter is the sample attrition problem [17]. To circumvent this effect, a brute-force approach is to increase the number of particles, but this makes the analysis of particle filters computationally expensive. Empirically, the requirement of number of samples can be estimated, although this bound in practice is loose and usually data/problem dependent. On the contrary, there are two ad-hoc approaches to alleviate the sample dispersion problem: (1) re-sampling the particles and (2) a good choice of proposal distribution. It should be noted that resampling does not really prevent the weight degeneracy problem; it just saves the calculation time by discarding the particles associated with insignificant weights. What really it does is artificially concealing the impoverishment by replacing the high important weights with many replicates of particles, thereby introducing high correlation between particles. A complete survey on the various re-sampling techniques can be found in [18], but it is beyond the scope of this work. In [19], for the accurate reconstruction of the state vector of a DC motor, the ascendancy of the particle filter at the cost of larger computational effort against the Kalman Filter, which assumes Gaussian measurement noise, is exposed.

As stated above, particle filters can also be cast in the framework of importance sampling [15], which allows the designer to freely choose the proposal distribution from which the particles are drawn. The selection of a suitable form of importance function to replace the true posterior density is a crucial step in the particle filter. In general, it is very difficult to design such proposal distributions and the choice is highly problem dependent. One of the most popular realizations of this approach uses the 'transition prior' as the importance proposal. But this deceptively simple approach, sometimes results in a higher uncertainty, because it fails to incorporate the latest available information from the most recent measurement. As pointed out in [16], in almost all successful implementations of PF, the proposal density is obtained from an EKF or UKF. Within the particle filter framework, the EKF and UKF can be utilized for the proposal distribution that not only incorporate the latest observation, but also generate proposals which tend to overlap with the true posterior, more consistently. Employing the EKF and UKF to approximate the mean and the covariance of the proposal distribution for each particle is the central idea of PF-EKF and PF-UKF proposed by
Van Der Merwe, (2000). The inherent difference between the SIR-PF, PF-EKF and the PF-UKF is the proposal distribution. Results in [20], indicate that the particle filters with a proposal distribution obtained using the EKF and UKF outperform the other existing filters, both theoretically and empirically for scalar estimation problem. Recently, a novel approach is presented for generating the proposal distributions using the Constrained Extended Kalman Filter (C-EKF), Constrained Unscented Kalman Filter (C-UKF) and Constrained Ensemble Kalman Filter (CEnKF) and the simulation studies underline the crucial role played by the choice of proposal distribution in formulation of particle filters [21]. The interest in this problem is in fact, motivated by the encouraging results developed in this paper.

This paper aims to evaluate the use of various particle filtering schemes on the simulated model of a three phase induction motor through extensive Monte Carlo simulation studies, and hence to determine the state estimation scheme that is suitable for AC drive applications amongst the four variants. The SIR-PF, PF-EKF, PFUKF, UKF algorithms were designed, analyzed, implemented and their effectiveness is evaluated under three different circumstances viz., step changes in load torque, speed reversal and low speed operation. Computer simulations have been carried out in the presence of additive state and measurement uncertainties.

The organisation of the paper is as follows:- After the introduction in Section-1, Section-2 discusses in detail the formulation of SIR-PF, PF-EKF and PF-UKF algorithms for the state estimation of a three phase IM. Three phase induction motor model is described in Section-3. Simulation studies are reported in Section-4 and the main concluding remarks drawn from the analysis of the simulation results are discussed in Section-5.UKF algorithm is provided in the Appendix-A.

\section{STATE ESTIMATION}

Consider a nonlinear system represented by the following nonlinear differential equations:

$$
\begin{aligned}
& \frac{d x}{d t}=F[x(t), u(t)] \\
& y=G[x(t), u(t)]
\end{aligned}
$$

Equation (1) is a state equation and equation (2) describes the relation between state and measurement variables. In order to describe a discrete nonlinear system, equations (1) and (2) can be functionally represented in discrete form as:

$$
\begin{aligned}
& \mathrm{x}(\mathrm{k})=\mathrm{f}[\mathrm{x}(\mathrm{k}-1), \mathrm{u}(\mathrm{k}-1)]+\mathrm{w}(\mathrm{k}) \\
& \mathrm{y}(\mathrm{k})=\mathrm{H}[\mathrm{x}(\mathrm{k}-1), \mathrm{u}(\mathrm{k}-1)]+\mathrm{v}(\mathrm{k})
\end{aligned}
$$

where $\mathrm{x}(\mathrm{k}) \in \mathrm{R}^{\mathrm{n}}$ is the system state vector, $\mathrm{u}(\mathrm{k}) \in \mathrm{R}^{\mathrm{m}}$ is the known system input, $\mathrm{w}(\mathrm{k}) \in \mathrm{R}^{\mathrm{p}}$ is the state noise, $\mathrm{y}(\mathrm{k}) \in \mathrm{R}^{\mathrm{r}}$ is the measured variable and $\mathrm{v}(\mathrm{k}) \in \mathrm{R}^{\mathrm{r}}$ is the measurement noise . The parameter $\mathrm{k}$ represents the sampling instant and the symbol $\mathrm{f}$ is a (possibly non-linear) state transition function and $\mathrm{g}$ is a (possibly non-linear) measurement function.

The objective of the recursive Bayesian state estimation problem is to find the mean and variance of a random variable $\mathrm{x}(\mathrm{k})$ using the conditional probability density function $\mathrm{p}\left[\mathbf{x}(\mathrm{k}) \mid \mathbf{Y}^{(\mathrm{k})}\right] . \mathbf{Y}^{(\mathrm{k})}$ denotes the set of all the available measurements, 
i.e. $\mathrm{Y}^{\mathrm{k}} \triangleq\{\mathrm{y}(\mathrm{k}), \mathrm{y}(\mathrm{k}-1), \ldots\} . \quad$ As reported in [14], the posterior density $\mathrm{p}\left[\mathbf{x}(\mathrm{k}) \mid \mathbf{Y}^{\mathrm{k}}\right]$ is estimated in two steps: (a) prediction step, which is computed before obtaining an observation, and, (b) update step, which is computed after obtaining an observation. In the prediction step, the posterior density $\mathrm{p}\left[\mathbf{x}(\mathrm{k}-1) \mid \mathbf{Y}^{\mathrm{k}-1}\right]$ at the previous time step is propagated into the next time step through the transition density $\{\mathrm{p}[\mathbf{x}(\mathrm{k}) \mid \mathbf{x}(\mathrm{k}-1)]\}$ as follows:

$$
\mathrm{p}\left[\mathbf{x}(\mathrm{k}) \mid \mathbf{Y}^{\mathrm{k}-1}\right]=\int \mathrm{p}[\mathbf{x}(\mathrm{k}) \mid \mathbf{x}(\mathrm{k}-1)] \mathrm{p}\left[\mathbf{x}(\mathrm{k}-1) \mid \mathbf{Y}^{\mathrm{k}-1}\right] \mathrm{d} \mathbf{x}(\mathrm{k}-1)
$$

The update stage involves the application of Bayes' rule:

$$
\mathrm{p}\left[\mathbf{x}(\mathrm{k}) \mid \mathbf{Y}^{\mathrm{k}}\right]=\frac{\mathrm{p}[\mathbf{y}(\mathrm{k}) \mid \mathbf{x}(\mathrm{k})]}{\mathrm{p}\left[\mathbf{y}(\mathrm{k}) \mid \mathbf{Y}^{\mathrm{k}-1}\right]} \times \mathrm{p}\left[\mathbf{x}(\mathrm{k}) \mid \mathbf{Y}^{\mathrm{k}-1}\right]
$$

Where,

$$
\mathrm{p}\left[\mathbf{y}(\mathrm{k}) \mid \mathbf{Y}^{\mathrm{k}-1}\right]=\int \mathrm{p}[\mathrm{y}(\mathrm{k}) \mid \mathrm{x}(\mathrm{k})] \mathrm{p}\left[\mathbf{x}(\mathrm{k}) \mid \mathbf{Y}^{\mathrm{k}-1}\right] \mathrm{d} \mathbf{x}(\mathrm{k})
$$

Combining 5, 6 and 7

$\mathrm{p}\left[\mathbf{x}(\mathrm{k}) \mid \mathbf{Y}^{\mathrm{k}}\right]=\frac{\mathrm{p}[\mathrm{y}(\mathrm{k}) \mid \mathbf{x}(\mathrm{k})]\left[\int \mathrm{p}[\mathbf{x}(\mathrm{k}) \mid \mathbf{x}(\mathrm{k}-1)] \mathrm{p}\left[\mathbf{x}(\mathrm{k}-1) \mid \mathbf{Y}^{\mathrm{k}-1}\right] \mathrm{d} \mathbf{x}(\mathrm{k}-1)\right]}{\int \mathrm{p}[\mathrm{y}(\mathrm{k}) \mid \mathrm{x}(\mathrm{k})] \mathrm{p}\left[\mathbf{x}(\mathrm{k}) \mid \mathbf{Y}^{\mathrm{k}-1}\right] \mathrm{d} \mathbf{x}(\mathrm{k})}$

Equation (8) describes how the conditional posterior density function propagates from $\mathrm{p}\left[\mathbf{x}(\mathrm{k}-1) \mid \mathbf{Y}^{\mathrm{k}-1}\right]$ to $\mathrm{p}\left[\mathbf{x}(\mathrm{k}) \mid \mathbf{Y}^{\mathrm{k}}\right]$. The properties of the state transition equation (3) are accounted through the transition density function $\mathrm{p}[\mathbf{x}(\mathrm{k}) \mid \mathbf{x}(\mathrm{k}-1)]$ while $\mathrm{p}[\mathbf{y}(\mathrm{k}) \mid \mathbf{x}(\mathrm{k})]$ reflects the non-linear measurement function. The prediction and update strategy provides an optimal solution to the state estimation, which unfortunately involves high-dimensional integration. The exact analytical solution to the recursive propagation of the posterior density is very difficult to obtain.

\subsection{Particle Filter Algorithm with EKF and UKF as Proposal Distribution}

The PF is a numerical method for implementing an optimal recursive Bayesian filter by Monte-Carlo simulation. Classical particle filters can be used to approximate the distribution $\mathrm{p}\left[\mathrm{x}(\mathrm{k}) \mid \mathrm{Y}^{\mathrm{k}}\right]$, using a set of random samples $\left\{\mathrm{x}^{\mathrm{i}}(\mathrm{k}), \mathrm{i}=1 \ldots . \mathrm{N}\right\}$ with associated weights $\left\{\mathrm{w}_{\mathrm{i}}(\mathrm{k}), \mathrm{i}=1 \ldots \ldots \mathrm{N}\right\}$ : $\mathrm{p}\left[\mathrm{x}(\mathrm{k}) \mid \mathrm{Y}^{\mathrm{k}}\right] \approx \sum_{\mathrm{i}}^{\mathrm{N}} \mathrm{w}^{(\mathrm{i})}(\mathrm{k}) \delta\left[\mathrm{x}(\mathrm{k})-\mathrm{x}^{(\mathrm{i})}(\mathrm{k})\right]$

The weights are normalized such that the weights sum to unity. In the above equation $\delta\left[x(k)-x^{i}(k)\right]$ is Dirac's delta function, $\quad \delta\left[\mathrm{x}(\mathrm{k})-\mathrm{x}^{\mathrm{i}}(\mathrm{k})\right]=1 \quad$ if $\quad \mathrm{x}(\mathrm{k})=\mathrm{x}^{\mathrm{i}}(\mathrm{k}) \quad$ and $\delta\left[\mathrm{x}(\mathrm{k})-\mathrm{x}^{\mathrm{i}}(\mathrm{k})\right]=0$ otherwise. It should be noted that drawing samples from the posterior density is not possible, although the posterior density can be easily evaluated at discrete points in the state space. For this reason a proposal density is used, and at each sampling instant, the samples are drawn from the proposal distribution. Further weights are computed to compensate for the difference between the proposal density and the true posterior density [14], and are defined as follows:

$$
\begin{aligned}
\widetilde{\omega}_{\mathrm{i}}(\mathrm{k}) & =\frac{\mathrm{p}\left[\mathrm{x}^{(\mathrm{i})}(1: \mathrm{k}) \mid \mathrm{Y}^{\mathrm{k}}\right]}{\mathrm{q}\left[\mathrm{x}^{(\mathrm{i})}(1: \mathrm{k}) \mid \mathrm{Y}^{\mathrm{k}}\right]} \\
& =\frac{\mathrm{p}\left[\mathrm{y}(\mathrm{k}) \mid \mathrm{x}^{(\mathrm{i})}(\mathrm{k})\right] \mathrm{p}\left[\mathrm{x}^{(\mathrm{i})}(\mathrm{k}) \mid \mathrm{x}^{(\mathrm{i})}(\mathrm{k}-1)\right]}{\mathrm{q}\left[\mathrm{x}^{(\mathrm{i})}(\mathrm{k}) \mid \mathrm{x}^{(\mathrm{i})}(\mathrm{k}-1), \mathrm{Y}^{\mathrm{k}}\right]} \widetilde{\omega}_{\mathrm{i}} \\
\omega_{\mathrm{i}}(\mathrm{k}) & =\frac{\widetilde{\omega}_{\mathrm{i}}(\mathrm{k})}{\sum_{\mathrm{j}=1}^{\mathrm{N}} \widetilde{\omega}_{\mathrm{j}}(\mathrm{k})}
\end{aligned}
$$

The above equation provides a mechanism to sequentially update the weights. The updated state estimates $\hat{X}(k \mid k)$ at the $k^{\text {th }}$ sampling instant are given by

$$
\left.\mathrm{E}\left[\mathrm{x}(\mathrm{k}) \mid \mathrm{Y}^{\mathrm{k}}\right)\right]=\sum_{\mathrm{i}=1}^{\mathrm{N}} \omega_{\mathrm{i}}(\mathrm{k}) \mathrm{x}^{(\mathrm{i})}(\mathrm{k})
$$

The computational steps involved are as follows [14]:

\subsubsection{Initialization}

At $\mathrm{k}=0, \mathrm{~N}$ samples are drawn from the given distribution of initial state $\hat{\mathbf{x}}(0 \mid 0)$. For example, if the initial state has multivariate normal distribution $N[\hat{\mathrm{x}}(0 \mid 0), P(0)]$, then the samples are drawn as follows:

$$
\begin{aligned}
& \hat{\mathbf{x}}^{(\mathrm{i})}(0 \mid 0)=\hat{\mathbf{x}}(0 \mid 0)+\mathrm{P}[0 \mid 0]^{1 / 2} \Upsilon^{(\mathrm{i})} \\
& \Upsilon^{(\mathrm{i})} \sim \mathrm{N}(0, \mathrm{I})
\end{aligned}
$$

and its associated weights are initialized as $\omega_{i}=\frac{1}{N}$. In the above equation $\mathrm{N}(\boldsymbol{\mu}, \boldsymbol{\Sigma})$, is a multivariate Gaussian density with argument mean $\mu$ and covariance $\Sigma$, i.e.

$$
\mathrm{N}[\mu, \Sigma]=(2 \Pi)^{-\mathrm{N} / 2}|\Sigma|^{-1 / 2} \exp \left[-0.5(\mathrm{x}-\mu)^{\mathrm{T}} \Sigma^{-1}(\mathrm{x}-\mu)\right]
$$

\subsubsection{Importance Sampling}

At the k'th time step, after obtaining measurement $y(k), N$ observers (EKF, UKF) are used in parallel to compute means and covariance of the proposal distributions, i.e. $\left\{\overline{\mathrm{x}}^{(\mathrm{i})}(\mathrm{k} \mid \mathrm{k}), \overline{\mathrm{P}}^{(\mathrm{i})}(\mathrm{k} \mid \mathrm{k})\right\} \quad$ for each propagated particle $\hat{\mathrm{X}}^{(\mathrm{i})}(\mathrm{k}-1 \mid \mathrm{k}-1)$. The importance density is then approximated as $\mathrm{q}\left[\mathrm{x}^{(\mathrm{i})}(\mathrm{k}) \mid \mathrm{x}^{(\mathrm{i})}(\mathrm{k}-1), \mathrm{Y}^{\mathrm{k}}\right] \approx \mathrm{N}\left[\mathrm{x}^{-(\mathrm{i})}(\mathrm{k} \mid \mathrm{k}), \overline{\mathrm{P}}^{(\mathrm{i})}(\mathrm{k} \mid \mathrm{k})\right.$ and used to draw a sample around each particle as follows: 


$$
\begin{aligned}
& \hat{\mathrm{x}}^{(\mathrm{i})}(\mathrm{k} \mid \mathrm{k})=\mathrm{x}^{-(\mathrm{i})}(\mathrm{k} \mid \mathrm{k})+\left[\mathrm{P}^{-(\mathrm{i})}(\mathrm{k} \mid \mathrm{k})\right] \gamma^{(\mathrm{i})} \\
& \gamma^{(\mathrm{i})} \sim \mathrm{N}(0, \mathrm{I})
\end{aligned}
$$

\subsubsection{Computation of weights}

The weights associated with each particle are now computed as follows:

$$
\tilde{\omega}_{\mathrm{i}}(\mathrm{k})=\frac{\mathrm{p}\left[\mathbf{y}(\mathrm{k}) \mid \mathbf{x}^{(\mathrm{i})}(\mathrm{k})\right] \mathrm{p}\left[\mathbf{x}^{(\mathrm{i})}(\mathrm{k}) \mid \mathbf{x}^{(\mathrm{i})}(\mathrm{k}-1)\right]}{\mathrm{q}\left[\mathbf{x}^{(\mathrm{i})}(\mathrm{k}) \mid \mathbf{x}^{(\mathrm{i})}(\mathrm{k}-1), \mathbf{Y}^{\mathrm{k}}\right]}\left(\frac{1}{\mathrm{M}}\right)
$$

These $\tilde{\omega}_{\mathrm{i}}(\mathrm{k})$ weights are then normalized to obtain $\left\{\omega_{\mathrm{i}}(\mathrm{k})\right\}$ as given by equation (10). In the special case when state and measurement noise signals are additive zero mean Gaussian white noise, the numerator can be computed as follows:

$$
\begin{aligned}
& \mathrm{p}\left[\mathrm{y}(\mathrm{k}) \mid \mathbf{x}^{(\mathrm{i})}(\mathrm{k})\right]=\mathrm{N}\left[\mathrm{H}\left[\hat{\mathbf{x}}^{\mathrm{i}}(\mathrm{k} \mid \mathrm{k})\right], \mathrm{R}\right] \\
& \mathrm{p}\left[\mathbf{x}^{(\mathrm{i})}(\mathrm{k}) \mid \mathbf{x}^{(\mathrm{i})}(\mathrm{k}-1)\right]=\mathrm{N}\left[\overline{\mathbf{x}}^{\mathrm{i}}(\mathrm{k} \mid \mathrm{k}-1), \mathrm{Q}\right]
\end{aligned}
$$

\subsubsection{Re-sampling}

This step involves discarding samples that have low importance and reassigning weights to the remaining particles. Various approaches have been suggested in the literature for carrying out this step. Arulampalam et al., have recommended the use of residual systematic re-sampling algorithm (RSR) and the resampling algorithm has been reported in [14]. At the end of this step, the sample set typically contains multiple replicas of important samples, thereby effectively increasing weight of these samples in the ensemble. It may be noted that, at the end of the resampling step, all samples are assigned equal weights, i.e. $\tilde{\omega}_{\mathrm{i}}(\mathrm{k}-1)=1 / \mathrm{N}$. The updated state estimate is next constructed as

$\left.\mathrm{E}\left[\mathbf{x}(\mathrm{k}) \mid \mathbf{Y}^{\mathrm{k}}\right)\right]=\frac{1}{\mathrm{~N}} \sum_{\mathrm{i}=1}^{\mathrm{N}} \hat{\mathrm{x}}^{(\mathrm{i})}(\mathrm{k} \mid \mathrm{k})$

\section{Remark - 1}

For SIR-PF, in the importance sampling step the state transition function is used as the proposal distribution/importance function, i.e. $\quad \mathrm{q}\left[\mathbf{x}^{(\mathrm{i})}(\mathrm{k}) \mid \mathbf{x}^{(\mathrm{i})}(\mathrm{k}-1), \mathbf{Y}^{\mathrm{k}}\right] \approx \mathrm{p}\left[\mathbf{x}^{(\mathrm{i})}(\mathrm{k}) \mid \mathbf{x}^{(\mathrm{i})}(\mathrm{k}-1)\right], \quad$ and samples are drawn from the above importance function.

\section{INDUCTION MOTOR MODEL}

The model of the three phase induction motor used for simulation is the rotor flux based extended model represented in stationary reference frame. The machine specifications used in this work is listed in Table 1. Differential equations for components of stator current, rotor fluxes and angular velocity of the induction motor in the frame of references connected to the stator are given as below [2]:

$$
\frac{\mathrm{di}_{\mathrm{s} \alpha}}{\mathrm{dt}}=\dot{X}_{1}=-\left[\frac{\mathrm{R}_{\mathrm{s}}}{\mathrm{L}_{\sigma}}+\frac{\mathrm{R}_{\mathrm{r}}^{\prime} \mathrm{L}_{\mathrm{m}}^{2}}{\mathrm{~L}_{\mathrm{r}}^{\prime} \mathrm{L}_{\sigma}}\right] \mathrm{i}_{\mathrm{s} \alpha}+\frac{\mathrm{R}_{\mathrm{r}}^{\prime} \mathrm{L}_{\mathrm{m}}}{\mathrm{L}_{\mathrm{r}}^{\prime} \mathrm{L}_{\sigma}} \psi_{\mathrm{r} \alpha}+\frac{\mathrm{L}_{\mathrm{m}}}{\mathrm{L}_{\sigma} \mathrm{L}_{\mathrm{r}}^{\prime}} \mathrm{P}_{\mathrm{p}} \omega_{\mathrm{m}} \psi_{\mathrm{r} \beta}+\frac{1}{\mathrm{~L}_{\sigma}} \mathrm{V}_{\mathrm{s} \alpha}
$$

$$
\begin{aligned}
& \frac{\mathrm{di}_{\mathrm{s} \beta}}{\mathrm{dt}}=\dot{\mathrm{X}}_{2}=-\left[\frac{\mathrm{R}_{\mathrm{s}}}{\mathrm{L}_{\sigma}}+\frac{\mathrm{R}_{\mathrm{r}}^{\prime} \mathrm{L}_{\mathrm{m}}^{2}}{\mathrm{~L}_{\mathrm{r}}^{2} \mathrm{~L}_{\sigma}}\right] \mathrm{i}_{\mathrm{s} \beta}+\frac{\mathrm{R}_{\mathrm{r}}^{\prime} \mathrm{L}_{\mathrm{m}}}{\mathrm{L}_{\mathrm{r}}^{2} \mathrm{~L}_{\sigma}} \psi_{\mathrm{r} \beta}-\frac{\mathrm{L}_{\mathrm{m}}}{\mathrm{L}_{\sigma} \mathrm{L}_{\mathrm{r}}^{\prime}} \mathrm{P}_{\mathrm{p}} \omega_{\mathrm{m}} \psi_{\mathrm{r} \alpha}+\frac{1}{\mathrm{~L}_{\sigma}} \mathrm{V}_{\mathrm{s} \beta} \\
& \frac{\mathrm{d} \psi_{\mathrm{r} \alpha}}{\mathrm{dt}}=\dot{\mathrm{X}}_{3}=\frac{\mathrm{R}_{\mathrm{r}}^{\prime}}{\mathrm{L}_{\mathrm{r}}^{\prime}} \mathrm{L}_{\mathrm{m}} \mathrm{i}_{\mathrm{s} \alpha}-\frac{\mathrm{R}_{\mathrm{r}}^{\prime}}{\mathrm{L}_{\mathrm{r}}^{\prime}} \psi_{\mathrm{r} \alpha}-\mathrm{P}_{\mathrm{p}} \omega_{\mathrm{m}} \psi_{\mathrm{r} \beta} \\
& \frac{\mathrm{d} \psi_{\mathrm{r} \beta}}{\mathrm{dt}}=\dot{\mathrm{X}}_{4}=\frac{\mathrm{R}_{\mathrm{r}}^{\prime}}{\mathrm{L}_{\mathrm{r}}^{\prime}} \mathrm{L}_{\mathrm{m}} \mathrm{i}_{\mathrm{s} \beta}-\frac{\mathrm{R}_{\mathrm{r}}^{\prime}}{\mathrm{L}_{\mathrm{r}}^{\prime}} \psi_{\mathrm{r} \beta}+\dot{\mathrm{X}}_{5}=-\frac{3}{2} \frac{\mathrm{P}_{\mathrm{p}}}{\mathrm{J}_{\mathrm{L}}} \frac{\mathrm{L}_{\mathrm{m}}}{\mathrm{L}_{\mathrm{r}}^{\prime}} \psi_{\mathrm{r} \beta} \mathrm{i}_{\mathrm{s} \alpha}+\frac{3}{2} \frac{\mathrm{P}_{\mathrm{p}}}{\mathrm{J}_{\mathrm{L}}} \frac{\mathrm{L}_{\mathrm{m}}}{\mathrm{L}_{\mathrm{r}}^{\prime}} \psi_{\mathrm{r} \alpha} \mathrm{i}_{\mathrm{s} \beta}-\frac{1}{\mathrm{~J}_{\mathrm{L}}} \mathrm{t}_{\mathrm{L}}
\end{aligned}
$$

The measurement equation is given by:

$$
\mathrm{Y}=\left[\begin{array}{ll}
\mathrm{i}_{\mathrm{s} \alpha} & \mathrm{i}_{\mathrm{s} \beta}
\end{array}\right]^{\mathrm{T}}
$$

The values of state variables were initialized as below:

$$
\mathrm{X}(0 \mid 0)=[0 ; 0 ; 0 ; 0 ; 0]
$$

The evolution of true state variables is computed by solving the non-linear differential equations, using the differential equation solver in MATLAB 7.7. The sampling time is chosen to be as 0.01 seconds and the length of all the simulation trials as 2000 , besides, the state and measurement noises are added in an additive fashion.

\subsection{Design of Particle Filtering Schemes}

The algorithm reported in Section 2.1, and in Appendix-A have been used to estimate the state variables of the IM and it may be noted that the filter models used for one step ahead prediction has load torque as an additional state variable which is of the form:

$$
\frac{\mathrm{dt}_{\mathrm{L}}}{\mathrm{dt}}=\dot{\mathrm{X}}_{6}=0
$$

Equation (21) implies that the load torque can vary only in a steplike fashion. The afore-said equation, together with the differential equations 15 to 19 , listed in the preceding sub-section have been used for generating one step ahead predicted state estimates. The state and measurement noise covariance matrices listed below in equations (22) and (23) were initialized as specified in [2]. However the variance linked with the augmented state variable is changed, to attain good responses.

$$
\begin{aligned}
& \mathrm{Q}_{\text {UKF,PF-EKF,SIR-PF, PF-UKF }}=\operatorname{diag}\left\{1.5 \times 10^{-11} \mathrm{~A}^{2} 1.5 \times 10^{-11} \mathrm{~A}^{2}\right. \\
& \left.10^{-15}(\mathrm{~V}-\mathrm{s})^{2} 10^{-15}(\mathrm{~V}-\mathrm{s})^{2} 10^{-15}(\mathrm{rad} / \mathrm{s})^{2} 10^{-6}(\mathrm{~N}-\mathrm{m})^{2}\right\} \\
& \mathrm{R}_{\text {UKF,PF-EKF,SIR-PF, PF-UKF }}=\operatorname{diag}\left\{1.5 \mathrm{e}^{-7} \mathrm{~A}^{2} 1.5 \mathrm{e}^{-7} \mathrm{~A}^{2}\right\}
\end{aligned}
$$

It is to be noted from equations (22) and (23) that test conditions for all the nonlinear filters are maintained identical during simulation. It has been assumed that the random errors were present in the noise covariance matrices and the estimation is started with the initial value as shown below:

$$
\mathrm{X}(0 \mid 0)=[0 ; 0 ; 0 ; 0 ; 0]
$$

The initial error covariance matrices reported in [2], has been fixed and is as follows: 
$\mathrm{P}=\operatorname{diag}\left\{1 \mathrm{~A}^{2} 1 \mathrm{~A}^{2} 1(\mathrm{~V}-\mathrm{s})^{2} 1(\mathrm{~V}-\mathrm{s})^{2} 1(\mathrm{rad}-\mathrm{s})^{2} 1(\mathrm{~N}-\mathrm{m})^{2}\right\}$

For all the scenarios tested in our simulation analysis, the ensemble size for a single run of different particle filters is taken as 100 in order to get reasonable responses.

\section{SIMULATION RESULTS AND DISCUSSION}

\subsection{Test Results}

In order to elucidate the superior tracking performance of the sample based filtering schemes against the UKF, which is relatively a new member in the Kalman filter family, simulation studies have been performed with regard to three different scenarios reported in [2] and the simulation analysis is carried out in MATLAB7.7-R 2008(b) program on an Intel core 2 Duo Processor with $1.8 \mathrm{GHz} \mathrm{CPU}$ and $2 \mathrm{~GB}$ RAM. The result of running (single run) of the particle filter and its variants (i.e. the true and estimated state variables) for the low speed operation scenario, which is possible by constantly maintaining $\mathrm{v} / \mathrm{f}$ ratio and was documented as a serious challenge in the arena of IM drives is shown in Figure 1. Figure 2 gives the estimation performance of the nonlinear filters taken for comparative study, when the motor is subjected to step changes in load torque. Figure 3 illustrates the tracking performance of the derivative free filters for the speed reversal case, which is realized by changing the input frequency from $+50 \mathrm{~Hz}$ to $-50 \mathrm{~Hz}$. As a result of the problem of particle collapse, which is significantly reported in the literature of various research fields, the deceptively simple approach SIR-PF which uses transition prior as the proposal distribution, fails to track the augmented state variable that can be clearly visible from Figures 1,2 and 3. From the simulation results depicted in the figures, it can be deduced that the tendency for collapse of weights is virtually eliminated in the newer versions of the particle filter. Moreover, the estimation of the augmented state variable is found to be very precise for PF-EKF. The most worthy being paid attention to is that the PF-EKF is the best one over the other competing algorithms of its class.

\subsection{Performance Assessment}

The justification of the superiority of certain algorithms over the others even on a specific problem is also unfair without Monte Carlo simulations. The sum of squares of the estimation errors (SSEE) is chosen as the performance index, since it is commonly used in literatures and it facilitates quantitative comparison. In order to reduce the influences that the random error brings, 10 independent simulations are carried out to calculate the mean value of SSEE [13]. The required sample size depends strongly on the design of the particle filter and the problem addressed. For especially high dimensional systems, an enormous, infeasible number of samples are required to obtain satisfactory results. The ensemble or particle numbers of the PF-EKF, the SIR-PF and the PF-UKF were set to 50 and 75 respectively; for our simulations, it is found that 75 particles were enough to obtain good results. Increasing the number of particles additionally hardly made any sense. Table 2 summarizes the simulation results obtained for UKF. Tables 3, 4 and 5 exhibit the results for PF-EKF, PF-UKF and SIR-PF respectively. From the view point of the SSEE, the PF-EKF is superior to the PF-UKF and UKF. Table 4 clearly illustrates the larger time complexity of PF-UKF, which prevents from being applied in practice. From the tables, it can be inferred that there is a reduction in the SSEE, when the particle size is increased. For the estimation of hidden states of a three phase IM, $\mathrm{UKF}$ is restricted by its computational demand in the covariance propagation. The simulation results shown in figures indicate that the UKF and PF-EKF yield quite similar results for the scenarios tested, but the magnitude of error in the estimates of UKF is larger than that of PF-EKF which has led to a conclusion that it is a robust estimator than other approaches.

\section{CONCLUDING REMARKS}

The use of importance or proposal distributions is known to reduce the particle size and improve the estimation accuracy of the particle filter. Thus, the choice of appropriate nonlinear filter to generate the importance distribution is a crucial step in a PF formulation. There is no general choice and it is highly problem dependent. In this work, the feasibility of using unconstrained EKF and UKF as proposals for the estimation of hidden states of a three phase induction motor is established. The performances of the proposed particle filter formulations have been evaluated with regard to three scenarios and the results are compared with the UKF. Simulation results reveal that PF-EKF generates unbiased state estimates even with the modest number of particles and can be regarded as a better alternative for the state estimation problem of a three phase IM. The UKF is used as the surrogate of the EKF, which avoids costly calculation of the Jacobian matrices, but due to the non-linearity in the dynamic model of the system, the accuracy of UKF is said to be relatively poor than its counterpart. However, for systems with poor micro processing unit UKF is recommended. The time complexity excludes PF-UKF from being applied in practice. The main challenge in the PF implementation is the reduction in computation time which needs to be addressed.

\section{REFERENCES}

[1] R.E. Kalman, "A new approach to linear filtering and prediction problems," Journal of Basic Engineering (ASME), vol. 82, pp. 34-45, 1960.

[2] M. Barut, S. Bogosyan, and M. Gokasan, "Speed - Sensorless estimation for induction motors using extended Kalman filters," IEEE Trans. Ind. Electron., vol. 54, no. 1, pp. 272 280, Feb. 2007.

[3] S.Bogosyan, M.Barut, and M.Gokasan, "Braided extended Kalman filters for sensorless estimation in induction motors at high-low/zero speed,"IET Control Theory Appl., vol. 1, no. 4, pp. 987-998, 2007.

[4] M. Barut, S. Bogosyan, and M. Gokasan, "An EKF based estimator for speed sensorless vector control of induction motors," Elec. Power Compo. Syst., vol. 33, no.7, pp. 727744, 2005

[5] M. Barut, S. Bogosyan, and M. Gokasan, "Switching EKF technique for rotor and stator resistance estimation in speed sensorless control of IMs," Energy Conversion and Management, vol. 48, pp. 3120-3134, 2007.

[6] M. Barut, "Bi- Input- extended Kalman filter based estimation technique for speed-sensorless control of induction motors," Energy Conversion and Management, vol. 51, pp. 2032- 2040, 2010.

[7] Young-Real Kim, Seung-Ki Sul, and Min-Ho Park, "Speed sensorless vector control of induction motor using extended Kalman filter," IEEE Trans. Ind. Appl., vol. 30, no. 5, pp. 1225-1233, Sep./Oct.1994. 
[8] S.J.Julier, J.K.Uhlmann, and H.F. Durrant - Whyte, "A new method for the nonlinear transformation of means and covariances in filters and estimators," IEEE Trans. Autom. Contr., vol. 45, no. 3, pp. 477-482, Mar. 2000.

[9] S.J.Julier, and J. K.Uhlmann," Unscented filtering and nonlinear estimation," Proc. of the IEEE, vol. 92, no. 3, pp. 401-422, Mar. 2004.

[10] B.Akin, U.Orguner, A.Ersak, and M.Ehsani, "Simple Derivative-Free Nonlinear state observer for sensorless AC drives," IEEE/ASME Trans. Mechatronics, vol. 11, no. 5, pp. 634-643, Oct. 2006.

[11] S.Kumar, J. Prakash, and P. Kanagasabapathy, "A critical evaluation and experimental verification of Extended Kalman Filter, Unscented Kalman Filter and Neural State Filter for state estimation of three phase induction motor", Applied Soft Computing, vol.11, no. 3, pp. 3199-3208, 2011.

[12] R.Kandepu, B.Foss, and L.Imsland, "Applying the Unscented Kalman filter for nonlinear state estimation," Journal of Process Control, vol. 18, pp.753-768, 2008.

[13] K.Xiong, H.Y.Zhang, and C.W.Chan, "Performance evaluation of UKF-based nonlinear filtering," Automatica, vol. 42, pp. 261-270, 2006.

[14] A.Doucet, N.de freitas, and N.Gordon, Eds.,Sequential Monte Carlo methods in practice New York: SpringerVerlag, 2001.
[15]M.S.Arulampalam, S.Maskell, N.Gordon, and T.Clapp, A tutorial on Particle filters for online non-linear / nonGaussian Bayesian Tracking," IEEE Trans. Sig. Process., vol. 50, no. 2, pp. 174-188, 2002.

[16] F.Daum, "Nonlinear Filters: beyond the Kalman filter," IEEE A\&E systems Magazine, vol. 20, no. 8, pp. 57-69, 2005.

[17] P.J.Van Leeuwen, “A variance - minimizing filter for large scale applications" Monthly Weather Review, vol. 131, pp. 1190-1200.

[18] N.J.Gordon, D.J.Salmond, and A.F.M.Smith, "Novel approach to nonlinear/non-Gaussian Bayesian state estimation", IEE Proc.,-F, vol. 140, no. 2, pp. 107-113, 1993.

[19] Gerasimos G.Rigatos, "Particle and Kalman filtering for state estimation and control of DC motors," ISA Transactions, vol. 48, no.1, pp. 62-72, Jan. 2009.

[20] R.Van Der Merwe, A. Doucet, N. de Freitas, and Eric A.Wan, " The Unscented Particle Filter," Technical report CUED / F-INFENG / TR380, Cambridge University Engineering Department, Cambridge, United Kingdom.

[21] J. Prakash, S.C. Patwardhan, and S.L. Shah, "On the choice of importance distributions for unconstrained and constrained state estimation using particle filter," Journal of Process Control, vol. 21, no. 1, pp. 3-16, 2011
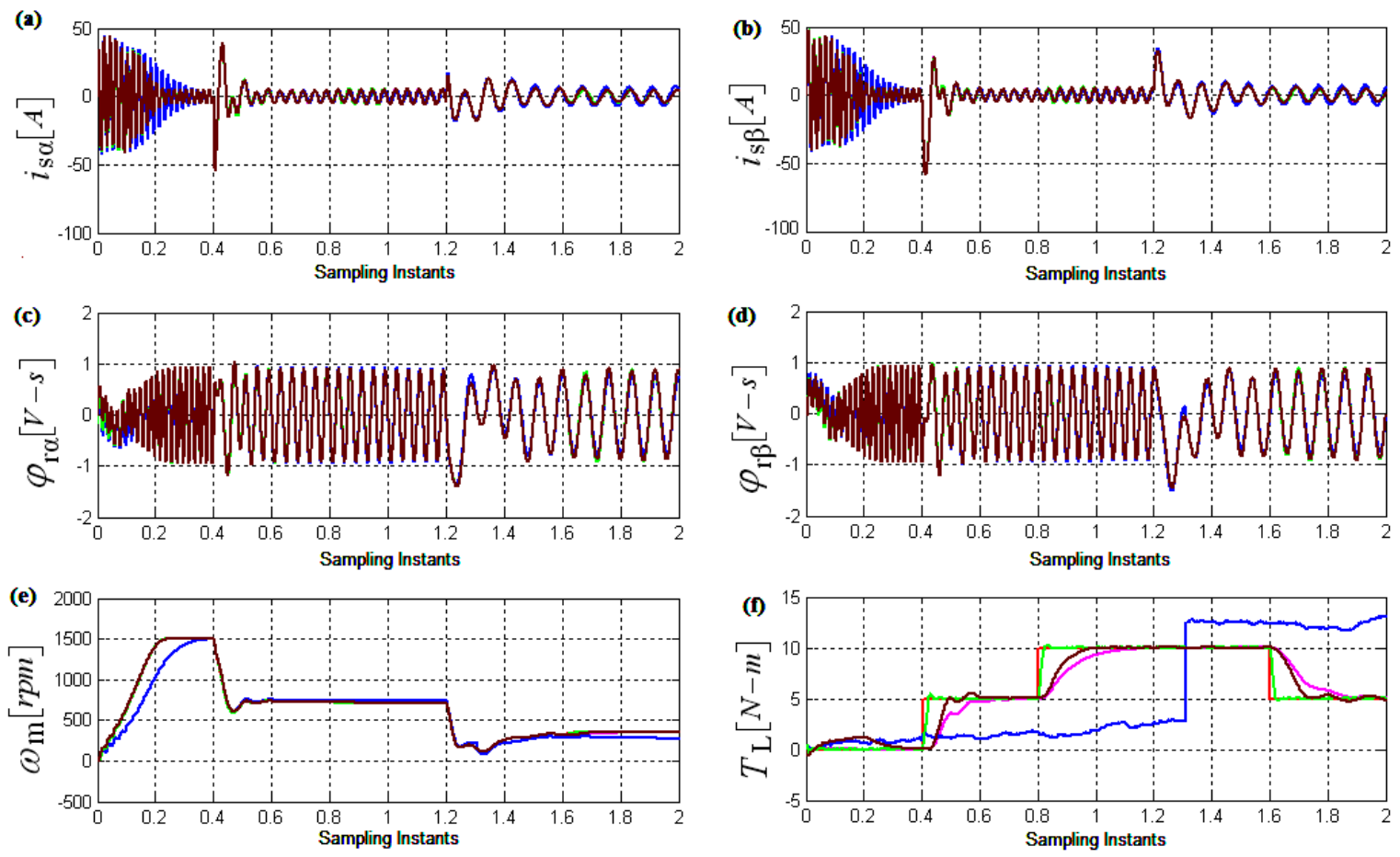

- True - UKF $\longrightarrow$ SIR-PF - PF-EKF - PF-UKF

Fig.1 Emergence of true and estimated state variables for low speed operation 

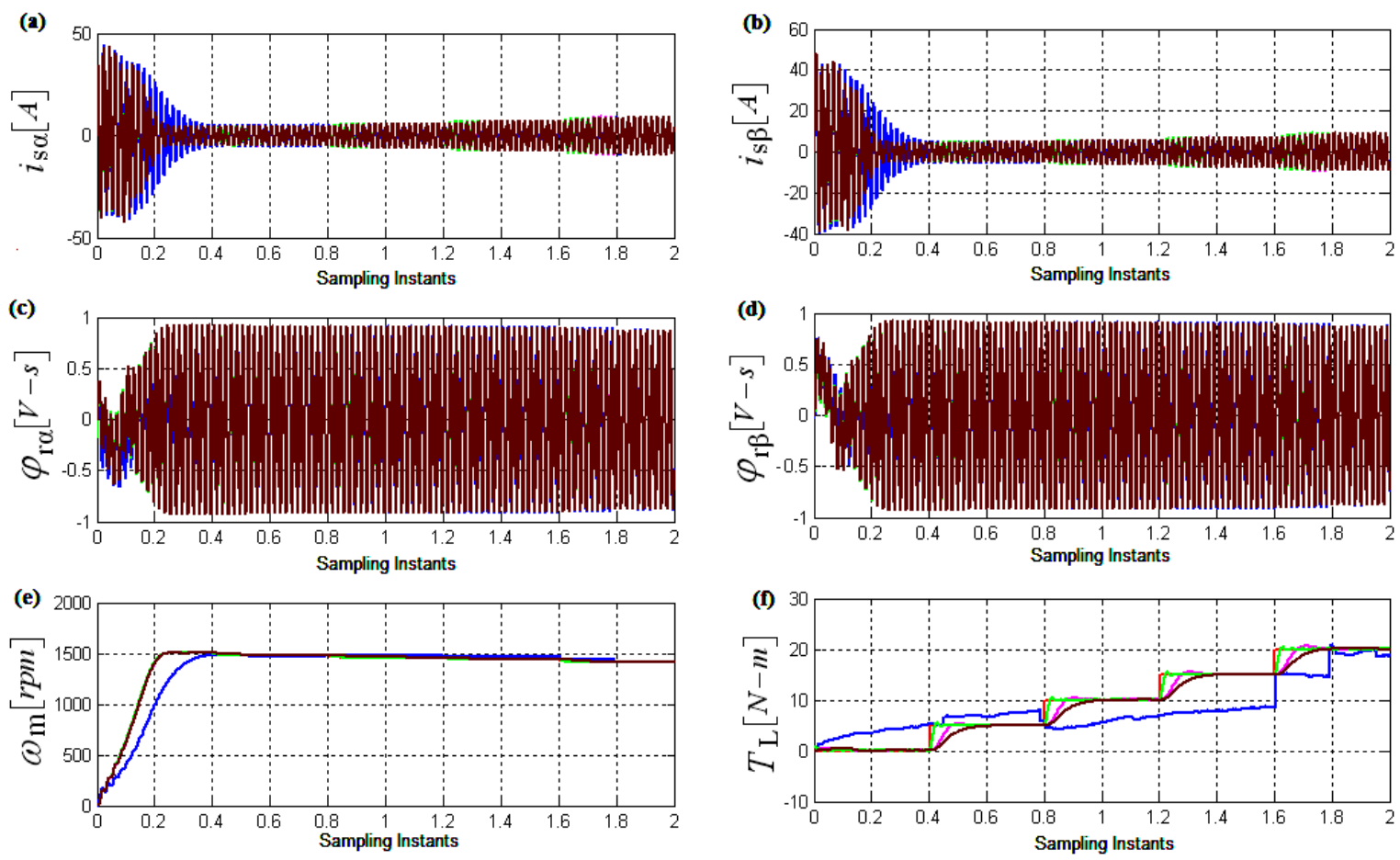

$\longrightarrow$ True $\longrightarrow$ UKF $\longrightarrow$ SIR-PF $\longrightarrow$ PF-EKF $\longrightarrow$ PF-UKF

Fig. 2 Evolution of true and estimated state variables for step changes in load torque
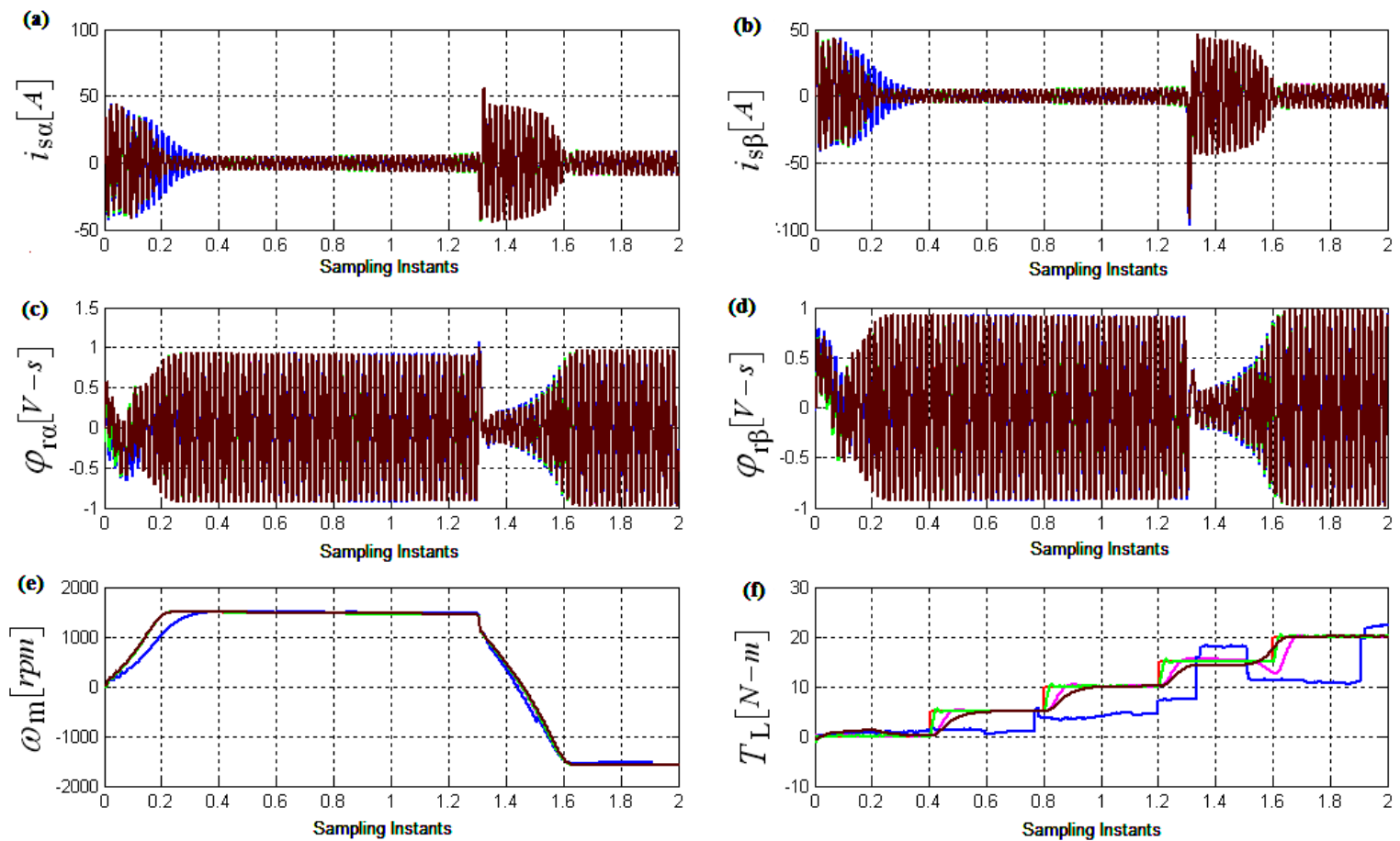

- True $\longrightarrow$ UKF - SIR-PF $\longrightarrow$ PF-EKF - PF-UKF

Fig. 3 Emergence of true and estimated state variables for speed reversal 
a) $i_{s \alpha}[A]$ - Stator stationary axis components of stator currents. b) $i_{s \beta}[A]$ - Stator stationary axis components of stator currents. c) $\psi_{\mathrm{r} \alpha}[\mathrm{V}-\mathrm{s}]$ - Rotor stationary axis components of stator flux. d) $\psi_{\mathrm{r} \beta}[\mathrm{V}-\mathrm{s}]$ - Rotor stationary axis components of stator flux. e) $\omega_{m}\left[\right.$ rad-s] - Angularvelocity. f) $T_{L}[N-m]$ - Load torque.

Table 1. Rated values and parameters of the IM used for simulation study

\begin{tabular}{|c|c|c|c|c|c|c|c|c|c|c|c|c|}
\hline $\mathbf{P}$ & $\mathbf{f}$ & $\mathbf{J}_{\mathbf{L}}$ & $\mathbf{P}_{\mathbf{p}}$ & $\mathbf{V}$ & $\mathbf{I}$ & $\mathbf{R}_{\mathbf{s}}$ & $\mathbf{R}_{\mathbf{r}}$ & $\mathbf{L}_{\mathbf{s}}$ & $\mathbf{L}_{\mathbf{r}}$ & $\mathbf{L}_{\mathbf{m}}$ & $\mathbf{N}_{\mathbf{m}}$ & $\mathbf{T}_{\mathbf{L}}$ \\
$\mathbf{( K W )}$ & $(\mathbf{H z})$ & $\left(\mathbf{K g} \cdot \mathbf{m}^{2}\right)$ & $\mathbf{( \mathbf { \Omega } )}$ & $\mathbf{( \mathbf { \Omega } )}$ & $\mathbf{( H )}$ & $\mathbf{( H )}$ & $\mathbf{( H )}$ & $(\mathbf{r p m})$ & $\mathbf{( N m )}$ \\
\hline 3 & 50 & 0.05 & 2 & 380 & 6.9 & 2.283 & 2.133 & 0.23 & 0.23 & 0.22 & 1430 & 20 \\
\hline
\end{tabular}

Table 2. Sum of Squares of the Estimation Error (SSEE) values of UKF

\begin{tabular}{|c|c|c|c|}
\hline $\begin{array}{c}\text { STATE } \\
\text { VARIABLES }\end{array}$ & SCENARIO I & SCENARIO II & SCENARIO III \\
\hline $\mathrm{i}_{\mathrm{s} \alpha}$ & $2.0954 \mathrm{e}^{-1}$ & $7.9398 \mathrm{e}^{-2}$ & $1.0726 \mathrm{e}^{-1}$ \\
\hline $\mathrm{i}_{\mathrm{s} \beta}$ & $2.0538 \mathrm{e}^{-1}$ & $7.9392 \mathrm{e}^{-2}$ & $1.0722 \mathrm{e}^{-1}$ \\
\hline$\Psi_{\mathrm{r} \alpha}$ & $4.3640 \mathrm{e}^{-4}$ & $3.8271 \mathrm{e}^{-5}$ & $5.1687 \mathrm{e}^{-5}$ \\
\hline$\Psi_{\mathrm{r} \beta}$ & $4.4223 \mathrm{e}^{-4}$ & $3.8269 \mathrm{e}^{-5}$ & $5.1663 \mathrm{e}^{-5}$ \\
\hline$\omega_{\mathrm{m}}$ & $5.8509 \mathrm{e}^{-1}$ & $2.6402 \mathrm{e}^{-1}$ & $6.6195 \mathrm{e}^{-1}$ \\
\hline $\mathrm{T}_{\mathrm{L}}$ & $1.8080 \mathrm{e}^{0}$ & $1.6652 \mathrm{e}^{0}$ & $2.1619 \mathrm{e}^{0}$ \\
\hline $\begin{array}{c}\text { Comp.Time Per } \\
\text { Samp.Instant }\end{array}$ & $6.8575 \mathrm{e}^{-2}$ & $7.1817 \mathrm{e}^{-2}$ & $7.2578 \mathrm{e}^{-2}$ \\
\hline
\end{tabular}

Table 3. Sum of Squares of the Estimation Error (SSEE) values of PF-EKF for different ensemble sizes

\begin{tabular}{|c|c|c|c|c|}
\hline PARTICLE SIZE & STATE VARIABLES & SCENARIO I & SCENARIO II & SCENARIO III \\
\hline \multirow{7}{*}{50} & $i_{s \alpha}$ & $2.0195 \mathrm{e}^{-5}$ & $5.8401 \mathrm{e}^{-5}$ & $5.7817 \mathrm{e}^{-5}$ \\
\hline & $i_{s \beta}$ & $3.8251 \mathrm{e}^{-5}$ & $5.9075 \mathrm{e}^{-5}$ & $5.8615 \mathrm{e}^{-5}$ \\
\hline & $\Psi_{\mathrm{r} \alpha}$ & $5.6519 \mathrm{e}^{-6}$ & $5.6808 \mathrm{e}^{-6}$ & $5.7025 \mathrm{e}^{-6}$ \\
\hline & $\Psi_{\mathrm{r} \beta}$ & $6.6786 \mathrm{e}^{-6}$ & $6.5854 \mathrm{e}^{-6}$ & $6.2762 \mathrm{e}^{-6}$ \\
\hline & $\omega_{\mathrm{m}}$ & $3.5731 \mathrm{e}^{-3}$ & $3.6262 \mathrm{e}^{-3}$ & $3.5891 \mathrm{e}^{-3}$ \\
\hline & $\mathrm{T}_{\mathrm{L}}$ & $2.8859 \mathrm{e}^{-1}$ & $3.7828 \mathrm{e}^{-1}$ & $3.7695 \mathrm{e}^{-1}$ \\
\hline & $\begin{array}{l}\text { Comp.Time Per } \\
\text { Samp.Instant }\end{array}$ & $1.1856 \mathrm{e}^{-2}$ & $1.2303 \mathrm{e}^{-2}$ & $1.2305 \mathrm{e}^{-2}$ \\
\hline \multirow{7}{*}{75} & $i_{s \alpha}$ & $2.0162 \mathrm{e}^{-5}$ & $5.8375 \mathrm{e}^{-5}$ & $5.7512 \mathrm{e}^{-5}$ \\
\hline & $i_{s \beta}$ & $3.8018 \mathrm{e}^{-5}$ & $5.9054 \mathrm{e}^{-5}$ & $5.8310 \mathrm{e}^{-5}$ \\
\hline & $\Psi_{\mathrm{r} \alpha}$ & $3.3528 \mathrm{e}^{-6}$ & $4.0986 \mathrm{e}^{-6}$ & $3.7562 \mathrm{e}^{-6}$ \\
\hline & $\Psi_{\mathrm{r} \beta}$ & $3.5083 \mathrm{e}^{-6}$ & $3.5298 \mathrm{e}^{-6}$ & $3.4806 \mathrm{e}^{-6}$ \\
\hline & $\omega_{\mathrm{m}}$ & $3.5443 \mathrm{e}^{-3}$ & $3.5784 \mathrm{e}^{-3}$ & $3.5719 \mathrm{e}^{-3}$ \\
\hline & $\mathrm{T}_{\mathrm{L}}$ & $2.8827 \mathrm{e}^{-1}$ & $3.7774 \mathrm{e}^{-1}$ & $3.7631 \mathrm{e}^{-1}$ \\
\hline & $\begin{array}{l}\text { Comp.Time Per } \\
\text { Samp.Instant }\end{array}$ & $1.1939 \mathrm{e}^{-2}$ & $1.2347 \mathrm{e}^{-2}$ & $1.2309 \mathrm{e}^{-2}$ \\
\hline
\end{tabular}


Table 4. Sum of Squares of the Estimation Error (SSEE) values of PF-UKF for different ensemble sizes

\begin{tabular}{|c|c|c|c|c|}
\hline PARTICLE SIZE & $\begin{array}{c}\text { STATE } \\
\text { VARIABLES }\end{array}$ & SCENARIO I & SCENARIO II & SCENARIO III \\
\hline \multirow{7}{*}{50} & $i_{s \alpha}$ & $3.9745 \mathrm{e}^{-3}$ & $2.5150 \mathrm{e}^{-3}$ & $1.6473 \mathrm{e}^{-3}$ \\
\hline & $\mathrm{i}_{\mathrm{s} \beta}$ & $3.7955 \mathrm{e}^{-3}$ & $2.5097 \mathrm{e}^{-3}$ & $1.6126 \mathrm{e}^{-3}$ \\
\hline & $\Psi_{\mathrm{r} \alpha}$ & $9.6121 \mathrm{e}^{-4}$ & $4.0498 \mathrm{e}^{-4}$ & $2.0880 \mathrm{e}^{-4}$ \\
\hline & $\Psi_{\mathrm{r} \beta}$ & $9.5744 \mathrm{e}^{-4}$ & $4.9944 \mathrm{e}^{-4}$ & $4.1732 \mathrm{e}^{-4}$ \\
\hline & $\omega_{\mathrm{m}}$ & $2.7727 \mathrm{e}^{-2}$ & $2.8790 \mathrm{e}^{-2}$ & $9.9504 \mathrm{e}^{-2}$ \\
\hline & $\mathrm{T}_{\mathrm{L}}$ & $3.5775 \mathrm{e}^{-1}$ & $3.5831 \mathrm{e}^{-1}$ & $1.5864 \mathrm{e}^{-1}$ \\
\hline & $\begin{array}{l}\text { Comp.Time Per } \\
\text { Samp.Instant }\end{array}$ & $1.2839 \mathrm{e}^{0}$ & $1.3758 \mathrm{e}^{0}$ & $1.8468 \mathrm{e}^{0}$ \\
\hline \multirow{7}{*}{75} & $i_{s \alpha}$ & $3.6726 \mathrm{e}^{-3}$ & $2.2866 \mathrm{e}^{-3}$ & $1.3457 \mathrm{e}^{-3}$ \\
\hline & $\mathrm{i}_{\mathrm{s} \beta}$ & $3.3922 \mathrm{e}^{-3}$ & $2.2300 \mathrm{e}^{-3}$ & $1.3391 \mathrm{e}^{-3}$ \\
\hline & $\Psi_{\mathrm{r} \alpha}$ & $1.0190 \mathrm{e}^{-4}$ & $3.5115 \mathrm{e}^{-4}$ & $1.2513 \mathrm{e}^{-4}$ \\
\hline & $\Psi_{\mathrm{r} \beta}$ & $1.1570 \mathrm{e}^{-4}$ & $2.9552 \mathrm{e}^{-4}$ & $1.5862 \mathrm{e}^{-4}$ \\
\hline & $\omega_{\mathrm{m}}$ & $1.8412 \mathrm{e}^{-2}$ & $1.9143 \mathrm{e}^{-2}$ & $1.0469 \mathrm{e}^{-2}$ \\
\hline & $\mathrm{T}_{\mathrm{L}}$ & $3.0370 \mathrm{e}^{-1}$ & $3.0121 \mathrm{e}^{-1}$ & $1.5837 \mathrm{e}^{-1}$ \\
\hline & $\begin{array}{l}\text { Comp.Time Per } \\
\text { Samp.Instant }\end{array}$ & $2.5539 \mathrm{e}^{0}$ & $2.8319 \mathrm{e}^{0}$ & $2.7562 \mathrm{e}^{0}$ \\
\hline
\end{tabular}

Table 5. Sum of Squares of the Estimation Error (SSEE) values of SIR-PF for different ensemble sizes

\begin{tabular}{|c|c|c|c|c|}
\hline $\begin{array}{l}\text { PARTICLE } \\
\text { SIZE }\end{array}$ & STATE VARIABLES & SCENARIO I & SCENARIO II & SCENARIO III \\
\hline \multirow{7}{*}{50} & $i_{s \alpha}$ & $2.7780 \mathrm{e}^{0}$ & $1.2192 \mathrm{e}^{0}$ & $1.7196 \mathrm{e}^{0}$ \\
\hline & $i_{s \beta}$ & $2.7832 \mathrm{e}^{0}$ & $1.2211 \mathrm{e}^{0}$ & $1.7194 \mathrm{e}^{0}$ \\
\hline & $\Psi_{\mathrm{r} \alpha}$ & $4.6752 \mathrm{e}^{-4}$ & $7.1731 \mathrm{e}^{-4}$ & $9.5485 \mathrm{e}^{-4}$ \\
\hline & $\Psi_{\mathrm{r} \beta}$ & $4.7303 \mathrm{e}^{-4}$ & $6.8811 \mathrm{e}^{-4}$ & $9.0541 \mathrm{e}^{-4}$ \\
\hline & $\omega_{\mathrm{m}}$ & $2.1904 \mathrm{e}^{1}$ & $9.9611 \mathrm{e}^{1}$ & $1.0577 \mathrm{e}^{1}$ \\
\hline & $\mathrm{T}_{\mathrm{L}}$ & $2.6255 \mathrm{e}^{1}$ & $1.5261 \mathrm{e}^{1}$ & $1.9468 \mathrm{e}^{1}$ \\
\hline & $\begin{array}{l}\text { Comp.Time Per } \\
\text { Samp.Instant }\end{array}$ & $4.1971 \mathrm{e}^{-1}$ & $4.3773 \mathrm{e}^{-1}$ & $4.4191 \mathrm{e}^{-1}$ \\
\hline \multirow{7}{*}{75} & $i_{s \alpha}$ & $2.9713 \mathrm{e}^{0}$ & $1.5628 \mathrm{e}^{0}$ & $1.3551 \mathrm{e}^{0}$ \\
\hline & $i_{s \beta}$ & $2.9810 \mathrm{e}^{0}$ & $1.5667 \mathrm{e}^{0}$ & $1.3570 \mathrm{e}^{0}$ \\
\hline & $\Psi_{\mathrm{r} \alpha}$ & $4.7352 \mathrm{e}^{-4}$ & $8.3332 \mathrm{e}^{-4}$ & $7.4044 \mathrm{e}^{-4}$ \\
\hline & $\Psi_{\mathrm{r} \beta}$ & $4.8665 \mathrm{e}^{-4}$ & $8.3147 \mathrm{e}^{-4}$ & $7.1514 \mathrm{e}^{-4}$ \\
\hline & $\omega_{\mathrm{m}}$ & $1.8679 \mathrm{e}^{1}$ & $1.5831 \mathrm{e}^{1}$ & $9.3100 \mathrm{e}^{1}$ \\
\hline & $\mathrm{T}_{\mathrm{L}}$ & $3.2397 \mathrm{e}^{1}$ & $1.6619 \mathrm{e}^{1}$ & $1.4669 \mathrm{e}^{1}$ \\
\hline & $\begin{array}{l}\text { Comp.Time Per } \\
\text { Samp.Instant }\end{array}$ & $6.8773 \mathrm{e}^{-1}$ & $5.8599 \mathrm{e}^{-1}$ & $4.5738 \mathrm{e}^{-1}$ \\
\hline
\end{tabular}




\section{Appendix - A}

Unscented Kalman Filter Algorithm (Julier and Uhlmann, 2000)

The unscented transformation (UT) is a method for calculating the statistics of a random variable, which undergoes a nonlinear transformation. A set of $2 \mathrm{~L}+1$ sigma points $\chi(\mathrm{k}-1 \mid \mathrm{k}-1, \mathrm{i})$ with the associated weights $\mathrm{w}(\mathrm{i})$ are chosen symmetrically about $\hat{\mathrm{X}}(\mathrm{k}-1 \mid \mathrm{k}-1)$ as follows:

$$
\begin{gathered}
\chi(\mathrm{k}-1 \mid \mathrm{k}-1,0)=\hat{\mathrm{x}}(\mathrm{k}-1 \mid \mathrm{k}-1) \quad \mathrm{w}_{0}=\frac{\kappa}{\mathrm{L}+\kappa} \\
\chi(\mathrm{k}-1 \mid \mathrm{k}-1, \mathrm{i})=\hat{\mathrm{x}}(\mathrm{k}-1 \mid \mathrm{k}-1)+(\sqrt{(\mathrm{L}+\kappa) \mathrm{P}(\mathrm{k}-1 \mid \mathrm{k}-1)})_{\mathrm{i}} \\
\chi\left(\mathrm{k}(\mathrm{i})=\frac{1}{2(\mathrm{~L}+\kappa)} \quad \mathrm{i}=1: \mathrm{L}\right. \\
\chi(\mathrm{k}-1 \mid \mathrm{k}-1, \mathrm{i})=\hat{\mathrm{x}}(\mathrm{k}-1 \mid \mathrm{k}-1)-(\sqrt{(\mathrm{L}+\kappa) \mathrm{P}(\mathrm{k}-1 \mid \mathrm{k}-1)})_{\mathrm{i}-\mathrm{L}} \mathrm{w}(\mathrm{i})=\frac{1}{2(\mathrm{~L}+\kappa)} ; \mathrm{i}=\mathrm{L}+1 \ldots .2 \mathrm{~L}
\end{gathered}
$$

Where $\kappa$ is a tuning parameter and for Gaussian distribution the tuning parameter can be obtained from the following relation $\kappa=3-\mathrm{L}$. The $2 \mathrm{~L}+1$ sigma points have been derived from the state $(\hat{\mathrm{x}}(\mathrm{k}-1 \mid \mathrm{k}-1))$ and covariance of the state vector $(\mathrm{P}(\mathrm{k}-1 \mid \mathrm{k}-1))$, where $\mathrm{L}$ is the dimension of the state.

In the prediction step the sigma points are propagated through the nonlinear differential equations to obtain the predicted set of sigma points as

$$
\chi^{*}(\mathrm{k} \mid \mathrm{k}-1, \mathrm{i})=\chi(\mathrm{k}-1 \mid \mathrm{k}-1, \mathrm{i})+\int_{(\mathrm{k}-1) \mathrm{T}}^{\mathrm{kT}} \mathrm{F}[\chi(\tau, \mathrm{i}), \mathbf{u}(\mathrm{k}-1)] \mathrm{d} \tau ; \mathrm{i}=0: 2 \mathrm{~L}
$$

The predicted state estimates $(\hat{\mathrm{x}}(\mathrm{k} \mid \mathrm{k}-1))$ is obtained from the predicted sigma points as

$$
\hat{\mathrm{x}}(\mathrm{k} \mid \mathrm{k}-1)=\sum_{\mathrm{i}=0}^{2 \mathrm{~L}} \mathrm{w}(\mathrm{i}) \chi^{*}(\mathrm{k} \mid \mathrm{k}-1, \mathrm{i})
$$

The error covariance matrix $(\mathrm{P}(\mathrm{k} \mid \mathrm{k}-1))$ is obtained from the predicted sigma points as

$$
\mathrm{P}(\mathrm{k} \mid \mathrm{k}-1)=\sum_{\mathrm{i}=0}^{2 \mathrm{~L}} \mathrm{w}(\mathrm{i})\left[\chi^{*}(\mathrm{k} \mid \mathrm{k}-1, \mathrm{i})-\hat{\mathrm{x}}(\mathrm{k} / \mathrm{k}-1)\right]\left[\left[\chi^{*}(\mathrm{k} \mid \mathrm{k}-1, \mathrm{i})-\hat{\mathrm{x}}(\mathrm{k} / \mathrm{k}-1)\right]^{\mathrm{T}}+\mathrm{Q}\right.
$$

The sigma points have to be redrawn in order to incorporate the effect of the additive process noise

$$
\begin{aligned}
& \chi(\mathrm{k} \mid \mathrm{k}-1,0)=\hat{\mathrm{x}}(\mathrm{k} \mid \mathrm{k}-1) \quad \mathrm{w}_{0}=\frac{\kappa}{\mathrm{L}+\kappa} \\
& \chi(\mathrm{k} \mid \mathrm{k}-1, \mathrm{i})=\hat{\mathrm{x}}(\mathrm{k} \mid \mathrm{k}-1)+(\sqrt{(\mathrm{L}+\kappa) \mathrm{P}(\mathrm{k} \mid \mathrm{k}-1)})_{\mathrm{i}} \quad \mathrm{w}(\mathrm{i})=\frac{1}{2(\mathrm{~L}+\kappa)} \quad \mathrm{i}=1: \mathrm{L} \\
& \chi(\mathrm{k} \mid \mathrm{k}-1, \mathrm{i})=\hat{\mathrm{x}}(\mathrm{k} \mid \mathrm{k}-1)-(\sqrt{(\mathrm{L}+\kappa) \mathrm{P}(\mathrm{k} \mid \mathrm{k}-1)})_{\mathrm{i}-\mathrm{L}} \quad \mathrm{w}(\mathrm{i})=\frac{1}{2(\mathrm{~L}+\kappa)} ; \mathrm{i}=\mathrm{L}+1 \ldots . .2 \mathrm{~L}
\end{aligned}
$$

The predicted sigma points are propagated through the nonlinear measurement equation to obtain the predicted measurement as

$$
\hat{\mathrm{y}}(\mathrm{k} \mid \mathrm{k}-1)=\sum_{\mathrm{i}=0}^{2 \mathrm{~L}} \mathrm{w}(\mathrm{i}) * \mathrm{H}[\chi(\mathrm{k} \mid \mathrm{k}-1, \mathrm{i})]
$$

The covariance matrix of the innovations $\left(\mathrm{P}_{\mathrm{ee}}(\mathrm{k})\right)$ and the cross covariance matrix between the predicted state estimate errors and innovations $\left(\mathrm{P}_{\varepsilon \mathrm{e}}(\mathrm{k})\right)$ are computed as:

$\mathrm{P}_{\mathrm{ce}}(\mathrm{k})=\left[\sum_{\mathrm{i}=0}^{2 \mathrm{~L}} \mathrm{w}(\mathrm{i})\{\mathrm{H}[\chi(\mathrm{k} \mid \mathrm{k}-1, \mathrm{i})]-\hat{\mathrm{y}}(\mathrm{k} \mid \mathrm{k}-1)\}^{*}\{\mathrm{H}[\chi(\mathrm{k} \mid \mathrm{k}-1, \mathrm{i})]-\hat{\mathrm{y}}(\mathrm{k} \mid \mathrm{k}-1)\}^{\mathrm{T}}\right]+\mathrm{R}$

$\mathrm{P}_{\varepsilon \mathrm{e}}(\mathrm{k})=\sum_{\mathrm{i}=0}^{2 \mathrm{~L}} \mathrm{w}(\mathrm{i})[\chi(\mathrm{k} \mid \mathrm{k}-1, \mathrm{i})-\hat{\mathrm{x}}(\mathrm{k} \mid \mathrm{k}-1)]^{*}\{\mathrm{H}[\chi(\mathrm{k} \mid \mathrm{k}-1, \mathrm{i})]-\hat{\mathrm{y}}(\mathrm{k} \mid \mathrm{k}-1)\}^{\mathrm{T}}$

$\Upsilon(\mathrm{k} \mid \mathrm{k}-1)=\mathrm{y}(\mathrm{k})-\hat{\mathrm{y}}(\mathrm{k} \mid \mathrm{k}-1)$

The Kalman gain matrix $(\mathrm{K}(\mathrm{k})$ ) can be determined as follows:

$$
\mathrm{K}(\mathrm{k})=\mathrm{P}_{\varepsilon \mathrm{e}}(\mathrm{k}) \mathrm{P}_{\mathrm{ee}}^{-1}(\mathrm{k})
$$

The updated state estimates $(\hat{\mathrm{x}}(\mathrm{k} \mid \mathrm{k}))$ are obtained using the linear update equation as in the Kalman filter.

$$
\hat{\mathrm{x}}(\mathrm{k} \mid \mathrm{k})=\hat{\mathrm{x}}(\mathrm{k} \mid \mathrm{k}-1)+\mathrm{K}(\mathrm{k}) \Upsilon(\mathrm{k} \mid \mathrm{k}-1)
$$

The covariance matrix of error in the updated state estimates $(\mathrm{P}(\mathrm{k} \mid \mathrm{k}))$ is computed using

$$
\mathrm{P}(\mathrm{k} \mid \mathrm{k})=\mathrm{P}(\mathrm{k} \mid \mathrm{k}-1)-\mathrm{K}(\mathrm{k}) * \mathrm{P}_{\mathrm{ee}}(\mathrm{k}) \mathrm{K}^{\mathrm{T}}(\mathrm{k})
$$

The UKF does not approximate the nonlinear functions of system and measurement models as required by the EKF. Instead, the nonlinear functions are applied to sigma points to yield transformed samples, and the propagated mean and covariance are calculated from the transformed samples. 